EXERCISE STUDIES IN CHILDREN

\section{Exercise Tests in Assessing Children with Lung or Heart Disease}

S. GODFREY The commonest symptom of children with lung or heart disease is shortness of breath on exertion or inability to exercise. Conventional tests at rest never really evaluate this complaint.

Almost all children of 5 and over can be persuaded to perform graded work on a cycle ergometer. Simply increasing the load every minute will reveal the effort tolerance and the pattern of ventilation, pulse and E.C.G. change. If more information is needed, expired gas is collected and analysed during steady state exercise and the mixed venous $\mathrm{CO}_{2}$ tension is measured simply and painlessly by a rebreathing method. A great deal can then be inferred about cardiac output, stroke volume and physiological dead space, but if definitive answers are required, or if desaturation is a problem, a small sample of arterialized blood is taken from an ear lobe.

Such tests, without the passage of a cardiac catheter and with minimal upset to the child, can determine the nature and severity of the disturbance and can be repeated as often as desired for follow-up during treatment.

\section{Exercise as a Tool for Studying Acute Changes in Airways Resistance}

N. M. CONNOLLY One of the most impressive features of children with asthma is the ease with which bronchoconstriction can be induced by exercise. Whereas cycling infrequently results in bronchoconstriction, running invariably does so. In this way we have studied the physiological effect of acute changes in airways resistance with particular reference to the respiratoryo movement of the chest.

This exercise-induced bronchoconstriction is prevented $\frac{\overline{\bar{c}}}{\overline{5}}$ by certain drugs and their action and duration in an $\mathbb{\AA}$ individual can be assessed by the methods described.

\section{Clinical Value of Exercise Tests in Childhood Asthma}

R. S. JONES The specific physiological abnormality in $\vec{\sim}$ asthma is the labile increase of airways resistance which can always be demonstrated. A fixed increase of airways or resistance may or may not also be present and is non-? specific.

The labile component is therefore the sine $q$ o non of asthma. The ventilatory response to exercise ando a bronchodilator drug may be used to provide an index of bronchial lability and thus form the basis for a physio- $-\vec{Z}$ logical classification (Jones, 1966). The test may be usedo to determine the mechanism of impaired exercise tolerance in a given asthmatic. There is a forme fruste of asthma in which excessive breathlessness on exertion $\vec{\theta}$ occurs without other symptoms or signs and the measure- $O$ ment of lability is the only technique available at present for establishing the diagnosis. It offers an objective method of assessment which can be used in the psychological evaluation of symptoms. It has proved of value in the long-term assessment of the effect of age on ventilatory function. A more rational use of other $\mathbb{D}$ therapeutic measures is possible. Desensitization and $\vec{F}$ disodium cromoglycate (Intal) therapy have proved to 3 be of most value in the highly labile (group 2) asthmatic, but not in those with a marked increase of fixed airways resistance (group 3), in whom ACTH and steroid may be indicated. 